

\section{Sumário}

I. Direito À Saúde e Políticas. 13

As Redes de Atenção à Saúde nos 30 anos do Sistema Único de Saúde: histórias, PROPOSTAS E DESAFIOS

Márcia Araújo Sabino de Freitas e Maria Rizoneide Negreiros de Araújo

DiREITO À SAÚdE PARA O RESIDENTE FRONTEIRIÇO: DESAFIO PARA A INTEGRALIDADE DO SUS .35 Fabrícia Helena Linhares Coelho da Silva Pereira, Livia Maria de Sousa e Tarin Cristino Frota Mont Alverne

Medidas provisórias e políticas públicas: Uma análise do PaPEl do Congresso NaCiOnal NAS POlíticas de SAÚde nO GOVERno Dilma $(2011-2016)$............................................55

Clóvis Alberto Bertolini de Pinho

Os LIMITES E A EXTENSÃo DA DEFESA DE DIREITOS FUNDAMENTAIS POR MEIO DE INSTRUMENTOS PROCESSUAIS DE COGNIÇÃo ESTREITA: MANDAdO DE SEGURANÇA E O CASO DA SAÚDE ...............76 Héctor Valverde Santana e Roberto Freitas Filho

DESENHANdo MOdElos de SISTEMAS de DISPUTAS PARA A ADMINISTRAÇÃo PÚbliCA: PROPOSIÇÕES ACERCA DA POLÍTICA PÚBLICA DE FORNECIMENTO DE MEDICAMENTOS PELO VIÉS DO DIÁLOGO INSTITUCIONAL

Mônica Teresa Costa Sousa e Maíra Lopes de Castro

O ACCOUNTABILITY DO SERVIÇO PÚBlico DE SAÚdE E A ATUAÇÃo INSTITUCIONAL NO ESTADO DO CEARÁ. 125 Mariana Dionísio de Andrade, Beatriz de Castro Rosa e Eduardo Régis Girão de Castro Pinto

Privacidade Relacional no ambulatório de oncogenética do hospital de Clínicas de Porto Alegre 146

Leonardo Stoll de Morais, Patrícia Ashton-Prolla, José Roberto Goldim e Márcia Santana Fernandes

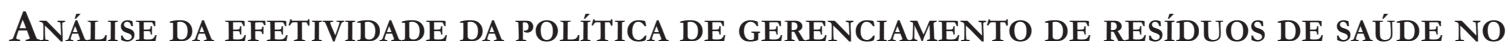
Município de SANTOS 175

Renato Braz Mehanna Khamis, Lígia Maria Comis Dutra e Thays Costa Nostre Teixeira

II. Direito À Saúde e Judicialização

Atuação da Defensoria Pública para a garantia do direito à saúde: A judicialização COMO INSTRUMENTO DE ACESSO À SAÚDE 195 Ramiro Nóbrega Sant'Ana 
A Judicialização do aCesso aos medicamentos em Belo Horizonte: UMA QUESTão sobre EQUIDADE.

Kammilla Éric Guerra de Araújo e Carlota Quintal

THE COURTS AND THE DELIVERY OF MEDICINES BY UNIFIED HEALTH SYSTEM IN BRAZIL: RECENT DEVELOPMENTS IN A DIFFICULT RELATIONSHIP BETWEEN JUDGES AND POLICY-MAKERS. 237 Eduardo Rocha Dias e Gina Vidal Marcílio Pompeu

Direito, SAÚde E SUICÍDIO: IMPACTOS DAS LEIS E DECISÕES JUDiCiAIS NA SAÚdE DOS JOVENS LGBT

Bruno Rafael Silva Nogueira Barbosa e Robson Antão de Medeiros

A Desproteção À SAÚde do TRABALHAdor e SUA JUdicialização Renata Salgado Leme e Luiz Pinto de Paula Filho

A judicialização da saúde sob o olhar da Análise Econômica do Direito: um exame dos INCENTIVOS AO AJUIZAMENTO E À SOLUÇÃo EXTRAJUdiCiAL DE CONFLITOS ..........................308 Victor Aguiar de Carvalho

III. Direito À SAúde e as Instituições de REgulação

A regulação da saúde Suplementar no Brasil: Perspectivas e ameaÇaS 329 Carlos Marden Cabral Coutinho e Taís Vasconcelos Cidrão

Os Mecanismos de Participação da Agência Nacional de Saúde Suplementar (ANS)343 Natasha Schmitt Caccia Salinas e Fernanda Martins

Papel institucional dos canais de reclamação para a Resolução extrajudicial de CONFLITOS SOBRE PLANOS DE SAÚDE: UMA ANÁLISE COMPARADA

Rafaela Magalhães Nogueira Carvalho, Antônio José Maristrello Porto e Bruno Araujo Ramalho

MedicAmentos SEM REgistros NA ANVISA: UMA ABORDAGEM INSTITUCIONAL .395 Igor De Lazari, Sergio Dias e Carlos Bolonha

A SUSTENTABILIDADE ECONÔMICO-FINANCEIRA DAS OPERADORAS DE PLANOS DE SAÚDE DIANTE DA CONCESSÃo INDISCRIMINADA DE TUTELAS DE URGÊNCIA NO BRASIL. 410 Álisson José Maia Melo e Nathalia Aparecida Sousa Dantas

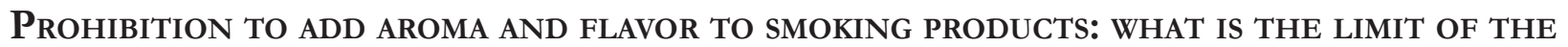
Regulatory power of the Brazilian Health Regulatory Agency? 435 Joedson de Souza Delgado e Ivo Teixeira Gico Júnior 


\title{
A judicialização da saúde sob o olhar da Análise Econômica do Direito: um exame dos incentivos ao ajuizamento e à solução extrajudicial de conflitos*
}

\author{
Right to health litigation from the \\ perspective of Economic Analysis of Law: a \\ study of incentives to file a lawsuit and to use \\ alternative methods of conflict resolution
}

Victor Aguiar de Carvalho**

\section{Resumo}

O Poder Judiciário recebe, diariamente, uma expressiva quantidade de demandas individuais em que se pleiteia, em face do Poder Público, o fornecimento das mais diversas prestações de saúde. A compreensão dos Magistrados em geral, quanto ao que estaria alcançado pelo direito constitucional à saúde, parece ser bastante abrangente, o que resulta em uma elevada probabilidade de êxito da demanda ajuizada. No presente artigo, em abordagem que não é usual na literatura, pretende-se analisar os incentivos atinentes à judicialização da saúde com base em dois diferentes aspectos. Em relação aos autores, argumenta-se que há diversos incentivos para o ajuizamento em massa de tais demandas, concluindo-se que, enquanto mantidos os mesmos incentivos, a propensão ao ajuizamento crescente permanecerá. No que tange à Administração Pública, aponta-se que há incentivos que deveriam levar à mais frequente busca pela solução extrajudicial de conflitos. Em conclusão, considerando-se a aparente pouca frequência de tais acordos extrajudiciais na prática da Administração, desenvolvem-se algumas possíveis hipóteses explicativas para tal quadro. A metodologia empregada envolve análise da literatura, pautada em bibliografia de autores do Direito e das ciências da saúde, além do emprego de instrumentos e raciocínios típicos da Análise Econômica do Direito para investigar o cenário examinado.

Palavras-chave: Judicialização da saúde. Incentivos. Análise econômica do direito.

* Recebido em 26/09/2018 Aprovado em 20/12/2018

** Doutorando e Mestre em Direito Público pela Universidade do Estado do Rio de Janeiro (UERJ). Pós-graduado em Direito do Estado e da Regulação pela Fundação Getúlio Vargas (FGV-Rio). Possui graduação em Direito pela Universidade do Estado do Rio de Janeiro (UERJ) e em Ciências Econômicas pela Pontifícia Universidade Católica do Rio de Janeiro (PUCRio). Procurador do Estado do Rio de Janeiro. Ex-Procurador do Estado do Espírito Santo. Advogado. E-mail: victoraguiar@pge.rj.gov.br.

\section{Abstract}

The Brazilian Judiciary receives every day an expressive number of lawsuits in which the Public Administration is requested to provide the most varied health benefits. The general judicial understanding related to what is connected to the constitutional right to health seems to be quite broad, which results in a high probability of success of these lawsuits. In this article, adopting an approach that is not usual in the literature, it is intended to analyze the incentives related to the public health litigation under two different aspects. In relation to 
the plaintiffs, it is argued that there are several incentives for the mass filing of such lawsuits, concluding that, while maintained the same incentives, the propensity for increasing the number of demands filled will remain stable. With regard to the Public Administration, it is highlighted that there are incentives that should lead to extrajudicial dispute resolutions more frequently. In conclusion, considering the apparent lack of such extrajudicial agreements, some possible explanatory hypotheses are developed. The methodology involves literature analysis, based on bibliography of the areas of Law and health sciences, as well as the use of tools and reasoning that are typical in the field of Economic Analysis of Law to investigate the scenario presented.

Keywords: Right to health litigation. Incentives. Economic analysis of law.

\section{INTRODUÇÃO}

O Poder Judiciário brasileiro recebe, diariamente, um número expressivo de demandas individuais nas quais se pleiteia, em face do Poder Público, o fornecimento das mais diversas prestações em saúde. Tal fenômeno, usualmente batizado de judicialização da saúde, acaba por consumir parcela relevante dos recursos humanos dos órgãos vinculados às funções essenciais à justiça, além de acarretar para o Estado (em sentido amplo) diversos custos atinentes à tramitação dos processos e ao atendimento das decisões judiciais.

Embora com certo atraso, as ciências jurídicas brasileiras gradativamente passaram a reconhecer a importância de pesquisas interdisciplinares para a melhor compreensão de fenômenos que, anteriormente, restavam analisados apenas por meio dos instrumentos e raciocínios tipicamente jurídicos.

Uma das diversas possibilidades de estudos interdisciplinares refere-se à Análise Econômica do Direito ${ }^{1}$. A associação entre Direito e Economia, cada vez mais usual em diversos ramos das ciências jurídicas, tem como um de seus méritos fazer com que os juristas concedam maior atenção aos “incentivos" gerados por normas, institutos ou fenômenos jurídicos. Por "incentivo", que é um jargão tipicamente econômico, entende-se, grosso modo, qualquer circunstância que impulsione ou motive uma pessoa a se comportar de uma determinada maneira².

Nessa toada, no presente trabalho, pretende-se analisar o sistema de incentivos relacionado à judicialização da saúde com base em dois diferentes enfoques: em primeiro lugar, serão examinados os incentivos que conduzem ao ajuizamento em massa de demandas da espécie. Posteriormente, analisar-se-á como tal realidade produz incentivos que podem ou poderiam influenciar o comportamento da Administração no sentido de buscar mais frequentemente a solução extrajudicial dos conflitos.

Para tanto, o artigo se dividirá em três seções, além da introdução e da conclusão. Na primeira se fará uma breve revisão acerca da realidade atual da judicialização em saúde e do entendimento dominante adotado pelo Judiciário. Em seguida, serão esmiuçados os incentivos relacionados ao frequente ajuizamento de feitos atinentes à pretensão de se obter prestações de saúde em face do Poder Público. Por fim, serão vistos os incentivos com os quais a Administração se depara e algumas hipóteses que, eventualmente, poderiam explicar o porquê de a solução extrajudicial dos conflitos ser incomum, apesar de, aparentemente, haver elementos que apontam para a racionalidade da composição amigável.

1 Segundo Nicholas Mercuro e Steven G. Medema, em obra introdutória sobre o tema, a denominada Análise Econômica do Direito como ramo interdisciplinar de estudo poderia ser brevemente definida como "a aplicação da teoria econômica - primariamente de microeconomia e dos conceitos básicos de economia do bem-estar - para examinar a formação, estrutura, processos e impacto econômico do Direito e das instituições legais". MERCURO, Nicholas; MEDEMA, Steven G. Economics and the Law: from Posner to Postmodernism and beyond. 2. ed. Princeton: Princeton University Press, 2006. p. 1.

2 Para uma explanação ilustrativa sobre a importância do conceito de incentivos para o pensamento econômico e sobre as suas reflexões na organização social, ver o capítulo denominado "Os incentivos, sempre eles...". GIAMBIAGI, Fabio. Capitalismo: modo de usar - porque o Brasil precisa aprender a lidar com a melhor forma de organização econômica que o ser humano já inventou. Rio de Janeiro: Elsevier, 2015. p. 211-232. 


\section{A REALIDADE ATUAL DA JUDICIALIZAÇÃO EM SAÚDE E O ENTENDIMENTO DOMINANTE ADOTADO}

PELO JUDICIÁRIO

É conhecido o quadro de vertiginoso crescimento na quantidade de processos em tramitação que versam sobre litígios relativos ao direito à saúde. Computando também os casos ajuizados em face de planos de saúde, que estão excluídos do escopo do presente trabalho, além das rotineiras demandas pelo fornecimento de medicamentos e de internações deduzidas em desfavor da Administração, apenas o Tribunal de Justiça do Estado do Rio de Janeiro recebeu, em 2017, 16.491 novas ações na área de saúde, que foram incorporadas a um acervo total de 566.229 feitos da espécie em tramitação naquele Tribunal ${ }^{3}$.

Não se trata de uma realidade exclusivamente fluminense. Segundo o Conselho Nacional de Justiça CNJ, no ano de 2011, tramitavam no Judiciário 240.980 processos judiciais na área de saúde 4 . Em 2016, foram recebidos, apenas pela primeira instância, 87.505 casos novos, grande parte relacionada ao fornecimento de medicamentos ou de tratamento médico-hospitalar ${ }^{5}$.

Especificamente quanto às demandas individuais para a obtenção do Poder Público de algum tipo de prestação de saúde, que são o escopo do presente estudo, os dados empíricos existentes indicam que tais pretensões são amplamente acolhidas pelo Judiciário. Em geral, a compreensão dos Magistrados quanto ao que estaria alcançado pelo direito à saúde constitucionalmente previsto parece ser bastante abrangente.

Com efeito, o Judiciário tende a conceder, usualmente, qualquer objeto demandado por um paciente que não apresente condições financeiras de arcar com aquele tratamento, desde que lhe seja devidamente prescrito por um médico, independentemente de esse profissional vincular-se à rede pública ou privada de saúde. O índice de êxito em ações da espécie já foi estimado em aproximadamente $90 \%$ dos $\operatorname{casos}^{6}$.

Pelo entendimento judicial dominante, a própria Constituição, por si só, já conferiria direta e imediatamente a todos o direito a qualquer prestação em saúde que lhes for prescrita, sendo certo que, na ausência do fornecimento do objeto pelo Poder Público, o bem poderia ser demandado judicialmente.

Nesse contexto, o volume de recursos públicos alocados para o cumprimento de decisões judiciais na matéria é cada vez mais expressivo. Em auditoria realizada pelo Tribunal de Contas da União, constatou-se que os gastos da União para aquisição de medicamentos ou insumos necessários para a satisfação de obrigações derivadas de processos judiciais foram de R $\$ 1$ bilhão no ano de 2015, enquanto, no ano de 2008, representavam apenas $\mathrm{R} \$ 70$ milhões. Tal incremento financeiro corresponde a, aproximadamente, $1.300 \% \%^{78}$.

A denominada judicialização da saúde não existe apenas em razão de eventuais falhas na execução de

3 RIO DE JANEIRO. Tribunal de Justiça do Rio de Janeiro. Processos na área de saúde atingem no TJRJ a marca de mais de meio milhão em 2017. Disponível em: http://www.tjri.jus.br/web/guest/home/-/noticias/visualizar/55518. Acesso em: 14 mar. 2018.

4 BRASIL. Conselho Nacional de Justiça. Brasil tem mais de 240 mil processos na área de saúde. Disponível em: http://www.cnj.jus.br/ noticias/cnj/56636-brasil-tem-mais-de-240-mil-processos-na-area-de-saude. Acesso em: 03 fev. 2018.

5 BRASIL. Conselho Nacional de Justiça. Justiça em números: demandas por classe e assunto - 2016. Disponível em: http:/ / paineis. cnj.jus.br/QvAJAXZfc/opendoc.htm?document=qvw_l\%2FPainelCNJ.qvw\&host=QVS\%40neodimio03\&anonymous=true\&sh eet=shResumoDespFT. Acesso em: 23 jan. 2018.

6 WANG, Daniel Wei Liang. Right to health litigation in Brazil: the problem and the Institutional Responses. Human Rights Law Review, v. 15, p. 617-641, 2015. p. 623; PRADO, Mariana Mota. The debatable role of courts in Brazil's health care system: does litigation harm or help? Journal of Law, Medicine and Ethics, v. 41, n. 1, p. 124-137, 2013. p. 125.

7 Tais valores referem-se apenas aos gastos contabilizados pelo Ministério da Saúde relativos ao cumprimento de decisões judiciais quando necessária a aquisição de medicamentos e insumos. Portanto, não incluem, por exemplo, montantes relativos a depósitos judiciais para satisfação das obrigações ou frete aéreo para a entrega dos medicamentos e insumos. Ou seja, o gasto total - de difícil contabilização final - é ainda maior. BRASIL. Tribunal de Contas da União. Aumentam os gastos públicos com judicialização da saúde. Disponível em: https:// portal.tcu.gov.br/imprensa/noticias/aumentam-os-gastos-publicos-com-judicializacao-da-saude.htm. Acesso em: 26 jan. 2018.

8 Tais valores referem-se apenas aos gastos contabilizados pelo Ministério da Saúde relativos ao cumprimento de decisões judiciais quando necessária a aquisição de medicamentos e insumos. Portanto, não incluem, por exemplo, montantes relativos a depósitos judiciais para satisfação das obrigações ou frete aéreo para a entrega dos medicamentos e insumos. Ou seja, o gasto total - de difícil contabilização final - é ainda maior. 
políticas públicas, como são os casos de falta de medicamentos ou de insumos padronizados para a dispensação pelo SUS em hospitais ou postos de saúde. Na verdade, é bastante frequente o pleito pelo recebimento de medicamentos que jamais foram inseridos na política farmacêutica do SUS (ou seja, que não são incorporados para dispensação regular pelo Poder Público). Já se apurou que demandas desse tipo representavam 80,6\% das ações sobre o tema no Estado do Rio de Janeiro e 92,5\% na capital ${ }^{9}$.

Além disso, o pleito por prestações que não foram padronizadas pelo Poder Público não se resume a casos em relação aos quais o SUS haja falhado no estabelecimento de um protocolo clinico, diretriz terapêutica ou na organização de uma política de qualquer natureza para tratamento da enfermidade. Em pesquisas, já se identificaram percentuais de $73 \%{ }^{10}$ ou $79 \%{ }^{11}$ quanto à parcela de medicamentos não padronizados cujo fornecimento fora determinado judicialmente, mas que apresentavam uma alternativa terapêutica ao seu uso disponível no SUS.

Apenas recentemente, já no ano de 2018, a Primeira Seção do Superior Tribunal de Justiça teve a oportunidade de enfrentar esse quadro quando do julgamento do recurso especial n ${ }^{\circ} 1.657 .156 / \mathrm{RJ}$, afetado pela sistemática dos recursos repetitivos para a definição do tema $\mathrm{n}^{\circ} 106$, concernente à obrigatoriedade do Poder Público de fornecer medicamentos não incorporados em atos normativos do SUS. Na oportunidade, o STJ decidiu que constitui obrigação do Poder Público o fornecimento de medicamentos, ainda que não incorporados pelo SUS, desde que presentes, cumulativamente, três requisitos: (i) comprovação, por meio de laudo médico fundamentado e circunstanciado expedido por médico que assiste o paciente, da imprescindibilidade ou necessidade do medicamento, assim como da ineficácia, para o tratamento da moléstia, dos fármacos fornecidos pelo SUS; (ii) incapacidade financeira do paciente de arcar com o custo do medicamento prescrito; e (iii) existência de registro do medicamento na Anvisa, observados os usos autorizados pela agência ${ }^{12}{ }^{13}$.

Considerando-se o pouco tempo decorrido desde o estabelecimento de novos parâmetros pelo STJ, bem como o fato de que, em razão da modulação ${ }^{14}$, não serem aplicados para processos já em curso, ainda não houve amadurecimento suficiente para se afirmar que o entendimento judicial passará a ser mais restritivo do que aquele que se assentava de maneira dominante até então e qual será o efetivo impacto do precedente do STJ na prática diária da judicialização em saúde.

Por outro lado, para os fins do presente trabalho, pelo teor do julgamento do recurso especial $\mathrm{n}^{\circ}$ 1.657.156/RJ, é possível constatar que o Judiciário, inequivocamente, consolidou o entendimento de que seria obrigação do Poder Público o fornecimento de medicamentos, ainda que não incorporados pelo SUS, desde que respeitados determinados requisitos estabelecidos.

As críticas à atual realidade da judicialização e ao entendimento adotado majoritariamente pelo Judiciário já foram exaustivamente deduzidas em diversos trabalhos acadêmicos, tanto no campo do Direito ${ }^{15}$, como das

9 Os dados foram compilados e citados por Daniel Wang, fazendo referência a outros estudos acadêmicos. WANG, Daniel Wei Liang. Right to health litigation in Brazil: the problem and the Institutional Responses. Human Rights Law Review, v. 15, p. 617-641, 2015. p. 619.

10 VIEIRA, Fabiola Sulpino; ZUCCHI, Paola. Distorções causadas pelas ações judiciais à política de medicamentos no Brasil. Revista Saúde Pública, v. 41, n. 2, p. 214-222, 2007. p. 218.

11 MACHADO, Marina Amaral de Ávila et al. Judicialização do acesso a medicamentos no Estado de Minas Gerais, Brasil. Revista de Saúde Pública, v. 45, n. 3, p. 590-598, 2011. p. 593.

12 Afastou-se, assim, também, a obrigatoriedade de fornecimento de medicamentos para uso off label, conforme restou estabelecido após julgamento de embargos de declaração opostos pelo Estado do Rio de Janeiro.

13 Para críticas quanto aos parâmetros estabelecidos pelo STJ. CARVALHO, Victor Aguiar de. A política pública na caneta do médico: avanços e incertezas no julgamento sobre fornecimento de medicamentos não incorporados ao SUS. Jota, 18 maio 2018. Disponível em: https://www.jota.info/opiniao-e-analise/artigos/a-politica-publica-na-caneta-do-medico-18052018. Acesso em: 15 set. 2018.

14 Estabeleceu-se a data de 4 de maio de 2018, quando houve a publicação do acórdão, como termo inicial da modulação dos efeitos.

15 BARCELLOS, Ana Paula de. O direito a prestações de saúde: complexidades, mínimo existencial e o valor das abordagens 
ciências da saúde ${ }^{16}$. No presente estudo, não se almeja revisitar tais críticas, mas sim analisar os incentivos que conduzem à judicialização em massa e como tal realidade, somada a uma jurisprudência amplamente desfavorável à Fazenda Pública, poderia ou deveria ser interpretada pela Administração a partir dos incentivos que gera.

\section{INCENTIVOS QUE CONDUZEM AO AJUIZAMENTO EM MASSA DE DEMANDAS POR PRESTAÇõES DE SAÚDE}

A decisão sobre o ajuizamento ou não de qualquer processo envolve um cálculo racional formulado pelo autor do pleito, ainda que de maneira meramente intuitiva. Uma demanda somente será levada ao Judiciário se o requerente considerar que o benefício por ele esperado com a lide superará os possíveis custos em que incorrerá para propô-la.

O proveito esperado pelo autor pode ser descrito como o benefício que pretende obter, ponderado pela probabilidade de que sua demanda seja julgada procedente. Se tal probabilidade é baixa, ainda que seja alto o benefício que em tese receberia na hipótese de acolhimento do pleito, o ajuizamento da pretensão não será uma estratégia atrativa.

Além disso, o autor há de considerar os custos nos quais incorrerá com o processo. Há custos de quatro diferentes ordens. Pode-se denominar o primeiro de custo pessoal. Estritamente relacionado com as circunstâncias pessoais de cada um, refere-se ao consumo de tempo próprio e às despesas nas quais se incorrerá para levar adiante a intenção de postular em juízo. Por hipótese, quem possua piores condições financeiras provavelmente terá um maior custo pessoal relativo, haja vista que terá de superar possíveis maiores dificuldades da vida, como a distância até uma localidade com melhores serviços, o preço do transporte até o local de atendimento, a despesa para reunir ou fotocopiar documentos, a impossibilidade de se ausentar do trabalho ainda que brevemente, dentre outros.

O segundo tipo de custo é o advocatício, seja em razão da necessidade de contratação de um profissional que detenha capacidade postulatória, seja pelo tempo despendido por aquele que litiga em causa própria. $\mathrm{O}$ terceiro se refere à antecipação das despesas concernentes ao ajuizamento da demanda e aos atos realizados ou requeridos no curso do processo ${ }^{17}$. Por fim, há os custos de sucumbência, como o pagamento de honorários advocatícios em benefício do patrono da parte contrária ${ }^{18}$ e o ressarcimento do vencedor quanto às despesas que antecipou.

coletiva e abstrata. Revista da Defensoria Pública do Estado de São Paulo, ano 1, n. 1, jul./dez. 2008; BARCELLOS, Ana Paula de. O direito constitucional à saúde: o caminho percorrido e algumas reflexões para o futuro. In: FERRARI, Sergio; MENDONÇA, José Vicente. Direito em público: homenagem ao professor Paulo Braga Galvão. Rio de Janeiro: Lúmen Juris, 2016; BARROSO, Luís Roberto. Da falta de efetividade à judicialização excessiva: Direito à Saúde, fornecimento gratuito de medicamentos e parâmetros para a atuação judicial. Disponível em: http://pfdc.pgr.mpf.mp.br/atuacao-e-conteudos-de-apoio/publicacoes/saude/Saude_-_judicializacao_-_Luis_Roberto_Barroso.pdf. Acesso em: 09 jan. 2018; FERRAZ, Octavio Luiz Motta. The right to health in the courts of Brazil: worsening health inequities? Health and Human Rights Journal, v. 11, n. 2, p. 33-45, 2009; TIMM, Luciano Benetti. Direito à saúde e a maneira mais eficiente de prover direitos fundamentais - uma perspectiva de direito e economia? In: NOBRE, Milton Augusto de Brito; SILVA, Ricardo Augusto Dias da (coord.). O CNJ e os desafios da efetivação do direito à saúde. 2. ed. Belo Horizonte: Fórum, 2013; SILVA, Virgílio Afonso da; TERRAZAS, Fernanda Vargas. Claiming the right to bealth in Brazilian courts: the exclusion of the already excluded. Disponível em: https://papers.ssrn.com/sol3/papers.cfm?abstract_id=1133620. Acesso em: 24 jan. 2018 ; WANG, Daniel Wei Liang. Right to health litigation in Brazil: the problem and the Institutional Responses. Human Rights Law Review, v. 15, p. 617-641, 2015.

16 VENTURA, Miriam et al. Judicialização da saúde, acesso à justiça e efetividade do direito à saúde. Physis - Revista de Saúde Coletiva, v. 20, n. 1, p. 77-100, 2010; VIEIRA, Fabiola Sulpino; ZUCCHI, Paola. Distorções causadas pelas ações judiciais à política de medicamentos no Brasil. Revista Saúde Pública, v. 41, n. 2, p. 214-222, 2007.

17 BRASIL. Lei n. 13.105, de 16 de março de 2015. Disponível em: http://www.planalto.gov.br/ccivil_03/_Ato2015-2018/2015/ Lei/L13105.htm. Acesso em: 15 set. 2018.

18 BRASIL. Lei n. 13.105, de 16 de março de 2015. Disponível em: http://www.planalto.gov.br/ccivil_03/_Ato2015-2018/2015/ Lei/L13105.htm. Acesso em: 15 set. 2018. 
Há de se observar, nos dois últimos casos, que tais custos dependem da probabilidade de a demanda ser julgada procedente ou não, bem como de a parte ré ser beneficiária da gratuidade de justiça. Se for julgada procedente, a parte autora, naturalmente, não incorrerá em ônus sucumbenciais, zerando tal despesa potencial. No mais, na hipótese de procedência, a parte contrária deverá ressarcir a vencedora quanto às despesas que adiantou para o ajuizamento, processamento e julgamento da demanda, embora, caso o vencido seja beneficiário da justiça gratuita, tal obrigação restará sob condição suspensiva de exigibilidade, extinguindo-se em cinco anos, a não ser que haja a improvável alteração da situação de insuficiência de recursos ${ }^{1920}$. Por outro lado, se a demanda for julgada improcedente, a parte autora arcará com as despesas que já antecipou, bem como com ônus sucumbenciais.

É natural que outros elementos subjetivos e inerentes às circunstâncias pessoais de um indivíduo também poderiam influenciar tal equação. Por exemplo, determinado autor pode auferir algum tipo de prazer apenas por litigar em juízo, no caso de acreditar, por hipótese, que assim está em busca da justiça como um valor por si só. Outros podem, o que não parece incomum, ter alguma satisfação por ajuizar uma demanda em face de uma pessoa específica. Todavia, por serem elementos imponderáveis, típicos das peculiaridades da condição humana, e por não se adequarem à racionalidade econômica estrita, tais questões serão aqui desconsideradas.

Termos matemáticos simples podem ajudar a melhor ilustrar o cálculo explicado. O valor esperado, para o autor, relativo ao ajuizamento de uma demanda (E(Ajuizamento)), poderia ser definido como $^{21}$ :

$$
\mathrm{E}(\text { Ajuizamento })=\mathrm{w} \cdot \mathrm{B}-(1-\mathrm{w}) \cdot \mathrm{Cs}-\mathrm{q} \cdot \mathrm{Cd}-\mathrm{Ca}-\mathrm{Cp}, \text { em que: }
$$

w - probabilidade de procedência da demanda;

B - benefício que pretende obter;

(1-w) - probabilidade de improcedência da demanda;

Cs - custos de sucumbência;

$\mathrm{Cd}$ - custos relativos às despesas antecipadas;

$\mathrm{q}$ - probabilidade de o autor arcar com os custos relativos às despesas antecipadas (Cd)., sendo que, caso o réu não seja beneficiário da gratuidade de justiça, $q=(1-w)$, uma vez que, se a pretensão autoral não for acolhida, deverá arcar com as despesas que antecipou; caso o réu seja beneficiário da gratuidade de justiça, q $=1$, já que, ainda que a demanda seja julgada procedente, a obrigação do réu de ressarci-lo em relação a tais despesas ficará sob condição suspensiva de exigibilidade, extinguindo-se na provável hipótese de não haver modificação do quadro;

Ca - custos com honorários contratuais do advogado ou com o próprio tempo, no caso de litigância em causa própria.

19 BRASIL. Lei n. 13.105, de 16 de março de 2015. Disponível em: http://www.planalto.gov.br/ccivil_03/_Ato2015-2018/2015/ Lei/L13105.htm. Acesso em: 15 set. 2018.

20 Nos termos do art. 98, $\int 3^{\circ}$, CPC, caso o beneficiário da gratuidade reste vencido, as obrigações decorrentes de sua sucumbência ficarão sob condição suspensiva de exigibilidade e somente poderão ser executadas se, nos 5 (cinco) anos subsequentes ao trânsito em julgado da decisão que as certificou, o credor demonstrar que deixou de existir a situação de insuficiência de recursos que justificou a concessão de gratuidade, extinguindo-se, passado esse prazo, tais obrigações do beneficiário. BRASIL. Lei n. 13.105, de 16 de março de 2015. Disponível em: http://www.planalto.gov.br/ccivil_03/_Ato2015-2018/2015/Lei/L13105.htm. Acesso em: 15 set. 2018.

21 Equações semelhantes podem ser vistas em: POSNER, Richard A. An Economic Approach to Legal Procedure and Judicial Administration. The Journal of Legal Studies, v. 2, n. 2, p. 399-458, jun. 1973. p. 419.; ARAKE, Henrique; GICO JUNIOR, Ivo. De graça, até injeção na testa: análise juseconômica da gratuidade de justiça. Economic Analysis of Law Review, v. 5, n. 1, p. 166-178, jan./ jun., 2014. p. 5. No entanto, a aqui apresentada parece, salvo melhor juízo, incorporar elementos adicionais da realidade processual brasileira. 
$\mathrm{Cp}-$ custos pessoais.

Assim, o ajuizamento de uma demanda judicial somente será buscado se o valor esperado relativo ao ajuizamento for maior ou igual a zero. Em outros termos:

$$
\text { w.B }-(1-w) \cdot C s-q \cdot C d-C a-C p \geq 0 .
$$

A equação acima modifica-se, consideravelmente, se o autor puder litigar sob o benefício da gratuidade de justiça. Em tal hipótese, nos termos do art. 98, CPC, o autor não arcará com os custos relativos às despesas antecipadas ou com os possíveis custos concernentes à potencial sucumbência. Em outros termos, Cs e Cd serão iguais a zero ${ }^{22}$.

Contextualizando a equação para o específico cenário do ajuizamento de demandas para obtenção de prestações sanitárias junto ao Poder Público, verifica-se que há diversos incentivos para a massificação desse tipo de pretensão.

A jurisprudência, conforme os dados já examinados, é amplamente favorável aos postulantes. Portanto, a probabilidade de procedência (w) é bastante alta, alcançando $90 \%$, como acima exposto. Se o objeto da demanda não for uma hipótese extrema, como a pretensão de se obter um medicamento sem registro na Anvisa ou um tratamento experimental, é possível considerar que a probabilidade de êxito ainda supere esse número.

Adicionalmente, o benefício almejado é considerável. Como visto, uma importante parcela dos processos concerne a objetos que não são padronizados pelo SUS para dispensação. Assim, a única possibilidade de o autor ter acesso gratuitamente a tais prestações é por meio do ajuizamento de uma demanda em face do Poder Público, na esperança de que o Judiciário determine à Administração que entregue, apenas para si, uma prestação que não é fornecida pelo SUS regularmente a todos os cidadãos.

Portanto, o proveito esperado com a judicialização é significativo, dado que a chance de improcedência é pequena e a via judicial é a única alternativa para obtenção gratuita do benefício almejado.

Além disso, os custos para ajuizamento são usualmente baixos. A prática forense, corroborada por pesquisa empírica ${ }^{23}$, indica que, em geral, os postulantes de prestações em saúde litigam sob o pálio da gratuidade de justiça ${ }^{24}$. Desse modo, não antecipam despesas que seriam necessárias para o ajuizamento da demanda. Em adição, ainda que a demanda seja julgada improcedente, não suportarão qualquer ônus sucumbencial.

Além disso, os custos advocatícios também podem ser nulos se a parte autora for patrocinada pela Defensoria Pública, o que deve se tornar cada vez mais usual, ante o fortalecimento desses importantes órgãos viabilizadores do acesso à justiça. $\mathrm{O}$ mesmo ocorre quando se litiga com o auxílio de patronos custeados

22 Há literatura em Análise Econômica do Direito que versa sobre elementos que levam à litigância temerária, a exemplo de ROSENBERG, David; SHAVELL, Steven. A model in which suits are brought for their nuisance value. Internacional Review of Law and Economics, v. 5, p. 3-13, 1985. Tratando-se especificamente dos incentivos produzidos pelo sistema de gratuidade de justiça para a litigância por vezes frívola. ARAKE, Henrique; GICO JUNIOR, Ivo. De graça, até injeção na testa: análise juseconômica da gratuidade de justiça. Economic Analysis of Law Review, v. 5, n. 1, p. 166-178, jan./jun., 2014.

23 Já se apurou que 85,5\% dos demandantes, em amostra de processos do estado do Paraná, obtiveram deferimento da gratuidade de justiça. PEREIRA, José Gilberto; PEPE, Vera Lúcia Edais. Acesso a medicamentos por via judicial no Paraná: aplicação de um modelo metodológico para análise e monitoramento das demandas judiciais. Revista de Direito Sanitário, v. 15, n. 2, p. 30-45, jul./out. 2014. p. 35.

24 Embora não sejam específicos para aqueles que litigam por prestações em saúde, os dados do CNJ demonstram a importância do benefício, inclusive em relação às despesas totais da Justiça. Desde o ano de 2011, nota-se a tendência de crescimento de tal participação, sendo que naquele ano representou $0,30 \%$ das despesas totais, frente a $0,45 \% \mathrm{em} \mathrm{2012,0,52 \%} \mathrm{em} 2013 \mathrm{e} 0,76 \%$ em 2014. No ano de 2015, identificou-se considerável redução, alcançando-se 0,51\% das despesas, sendo que em 2016 houve novo incremento, atingindo-se 0,59\%. BRASIL. Conselho Nacional de Justiça. Justiça em números: indicadores do Poder Judiciário em 2016 - Total. Disponível em: http://paineis.cnj.jus.br/QvAJAXZfc/opendoc .htm?document=qvw_l\%2FPainelCNJ.qvw\&host= QVS\%40neodimio03\&anonymous=true\&sheet=shResumoDespFT. Acesso em: 23 jan. 2018. 
pelo Poder Público (como na hipótese da designação de defensores dativos) ou por meio de advogados indicados por entidades de ensino (como nos escritórios modelos, vinculados a diversas faculdades de Direito no país). É de se ver que, em estados como o Rio de Janeiro e o Rio Grande do Sul, a maior parte dos demandantes já são patrocinados pela Defensoria Pública ${ }^{25}$.

Especificamente quanto às Defensorias Públicas, além da intenção de tutelar o direito fundamental à saúde de seus assistidos de acordo com a interpretação e extensão que lhe conferem, há, ainda, outros incentivos $^{26}$ que conduzem ao crescente ajuizamento de demandas. Em primeiro lugar, em relação aos custos suportados pelo órgão, os mais relevantes tendem a ser custos fixos, relacionados à estrutura física de atendimento e à remuneração de seu quadro de pessoal (Defensores, servidores, estagiários etc.). O ajuizamento de uma ação adicional representa um custo marginal que é diminuto em comparação aos custos fixos que serão inevitavelmente suportados, independentemente da quantidade de novas demandas propostas. Em outros termos, um processo a mais representa um custo muito pequeno para a instituição, que já está organizada para patrocinar milhares de causas.

Embora não se acredite que nenhum Defensor Público pense nesse aspecto quando toma a decisão de propor ou não uma pretensão em favor de um assistido seu, há de se observar, ainda, que a legislação vigente cria outro incentivo para o ajuizamento de demandas adicionais. Nos termos do art. $4^{\circ}$, XXI, da Lei Complementar $\mathrm{n}^{\circ}$ 80/1994, caso o feito seja julgado procedente, o órgão fará jus a receber verbas sucumbenciais decorrentes de sua atuação, que devem ser repassadas a fundos destinados exclusivamente ao aparelhamento da Defensoria Pública e à capacitação profissional de seus membros e servidores. Por outro lado, considerando-se que os assistidos em geral litigarão sob o pálio da gratuidade de justiça, caso a demanda seja julgada improcedente, não haverá qualquer ônus sucumbencial a ser suportado pelo autor ou pelo órgão. Em outros termos, o assistido e o órgão podem auferir um proveito pelo êxito das demandas sem que a parte autora incorra no risco de suportar um prejuízo.

Assim, pelas circunstâncias aduzidas, quais sejam, baixos custos marginais relativos ao ajuizamento de uma nova demanda e nenhum risco de custo sucumbencial para o assistido, ao se identificar qualquer probabilidade de êxito da pretensão, mostra-se uma escolha racional levá-la ao Judiciário. Na hipótese de dúvida real entre propor ou não uma demanda em favor de um assistido, os incentivos presentes indicam que o caminho natural e esperado será o do ajuizamento de mais um processo.

Por todo o quadro acima exposto, são expressivos os incentivos para que um indivíduo recorra ao Judiciário em busca de uma prestação em saúde. É a única via para acesso a prestações que a Administração não fornece por meio do SUS; em razão da jurisprudência dominante, a probabilidade de êxito é bastante elevada; os custos advocatícios ou de antecipação de despesas podem ser nulos; e ainda que a sua demanda não seja acolhida, o autor em muitos casos não arcará com nenhum custo sucumbencial.

Por outro lado, os desestímulos enfrentados, ao fim, pelos autores, podem se limitar aos seus custos pessoais, relacionados às despesas e dissabores próprios do cotidiano que enfrentarão para conseguir levar adiante a intenção de iniciar um processo. Em especial por se tratarem de portadores de alguma enfermidade e em geral hipossuficientes economicamente, tais obstáculos de fato podem não ser pequenos.

Novamente em termos matemáticos, considerando-se que, como analisado, em relação às demandas por prestações em saúde Cs, Cd e Ca, podem, usualmente, ser iguais a zero, o valor esperado para o ajuizamento

25 Conforme apontado por Daniel Wei Liang Wang, essa não é uma realidade nacional. Segundo os dados por ele compilados, à exceção do que ocorre nos estados do Rio de Janeiro e do Rio Grande do Sul, a maior parte dos litigantes são representados por advogados privados. WANG, Daniel Wei Liang. Courts as healthcare policy-makers: the problem, the responses to the problem and problems in the responses. Disponível em: http://bibliotecadigital.fgv.br/dspace/bitstream/handle/10438/11198/RPS_75_final. pdf? sequence=1\&isAllowed=y. Acesso em: 23 jan. 2018.

26 É importante esclarecer que o termo “incentivo" aqui novamente é empregado em seu caráter técnico. Analisa-se uma circunstância que impulsiona alguém a se comportar de uma determinada maneira. Não se refere a uma circunstância desabonadora ou a um questionamento subjetivo sobre a conduta adotada, mas sim a elementos que contribuem para que o comportamento se dê de uma determinada maneira. Portanto, de modo algum se pretende aqui realizar qualquer juízo subjetivo sobre os elementos analisados. 
de uma demanda no tema equivale a $\mathrm{E}$ (Ajuizamento) $=$ w.B $-\mathrm{Cp}$.

Ocorre que, como destacado, recorrer ao Judiciário será uma estratégia racional se o valor esperado relativo ao ajuizamento for maior ou igual a zero. No caso em exame, o ajuizamento deverá ser buscado se w.B $-\mathrm{Cp} \geq 0$. Ou, em outros termos, se w.B $\geq$ Cp.

Em que circunstâncias w.B $\geq$ Cp? Sempre que se considerar que o benefício a ser auferido, ponderado pela probabilidade de êxito, supera os dissabores pessoais a serem suportados quando se propõe uma ação. Não é difícil conceber que os custos pessoais serão frequentemente superados pela alta chance de êxito e pelo fato de a judicialização ser a única via para acesso, gratuitamente, a prestações que não são ou não estão sendo fornecidas pelo SUS.

Está posto o quadro de incentivos para a crescente massificação das demandas por prestações sanitárias, cenário que apenas tende a se agravar enquanto os elementos atualmente presentes permanecerem estáveis.

\section{Incentivos enfrentados pela Administração Pública}

Colocado o cenário enfrentado pela Administração Pública, formado, em síntese, por uma jurisprudência bastante desfavorável e por diversos elementos que apontam para a continuidade da judicialização em massa, passa-se a analisar como tais incentivos podem ou deveriam influenciar o comportamento adotado pelo Poder Público.

\subsection{Racionalidade da busca pela solução extrajudicial dos conflitos}

É legítimo que os entes públicos eventualmente discordem juridicamente do entendimento majoritariamente adotado pelo Judiciário quanto ao conteúdo do que se insere no direito fundamental à saúde. Todavia, ainda que possuam alguma aspiração de modificação futura da corrente interpretação judicial, no momento presente, a jurisprudência dos Tribunais pode ser encarada como um dado ou um fato posto que os entes réus precisam considerar quando da decisão por suas estratégias de conduta ou quando do desenho de suas organizações internas.

Reforçando a percepção de que a jurisprudência dominante é um fato posto, há de se observar que se encontram em julgamento os recursos extraordinários $n^{\text {os }} 566.471$ e 657.718, com repercussão geral reconhecida pelo STF, por meio dos quais a Corte pretende fixar, em definitivo, eventualmente até modificando a leitura recentemente realizada pelo STJ quanto ao tema, teses sobre a obrigação de fornecimento, respectivamente, de medicamentos que não se encontrem padronizados para dispensação no SUS e de fármacos sem registro na Anvisa. Ao menos até que ocorra o julgamento definitivo de tais recursos paradigmas, que eventualmente poderá em definitivo alterar o entendimento dominante no Judiciário, a Administração precisará lidar com a jurisprudência como sedimentada no momento e, nesse quadro, adotar escolhas econômica e processualmente racionais ${ }^{27}$.

Diversos elementos relacionados à judicialização da saúde indicam que a passiva aceitação do ajuizamento em massa de tais demandas não parece ser uma escolha eficiente para a Administração. Há vários incentivos que indicam que a mais frequente busca pela solução extrajudicial dos conflitos poderia ser uma estratégia racional e consentânea à economicidade

27 Por mais que o STJ, recentemente, haja estabelecido alguns parâmetros a serem observados quando do julgamento de demandas individuais em saúde, as questões jurídicas enfrentadas por aquela corte se sobrepõem às que ainda serão examinadas em definitivo pelo STF, razão pela qual se espera que apenas os precedentes em repercussão geral no Supremo Tribunal venham a consolidar o quadro jurídico. CARVALHO, Victor Aguiar de. A política pública na caneta do médico: avanços e incertezas no julgamento sobre fornecimento de medicamentos não incorporados ao SUS. Jota, 18 maio 2018. Disponível em: https://www.jota.info/opiniao-eanalise/artigos/a-politica-publica-na-caneta-do-medico-18052018. Acesso em: 15 set. 2018. 
Com efeito, a Análise Econômica do Direito apresenta raciocínios úteis para que se compreendam as hipóteses em que a celebração de um acordo, que é uma forma de solução cooperativa para o conflito, seria uma estratégia ótima para os envolvidos ${ }^{28}$. Em linhas gerais, pode-se afirmar que as partes estariam dispostas a celebrar um acordo extrajudicial sempre que, por essa via, conseguissem obter um resultado ao menos igual ao que esperariam conquistar por meio do litígio em juízo, já se computando os custos envolvidos e a probabilidade de êxito de cada um. Sob outra ótica, mas em idêntico caminho, Richard Posner aponta que a condição necessária para um acordo é a de que a oferta mínima que o potencial autor esteja disposto a aceitar seja inferior ao máximo que o eventual réu estaria disposto a conceder para evitar a disputa ${ }^{29}$.

Há ainda que se observar que, caso o possível réu pretenda solucionar extrajudicialmente seu conflito, também não restará livre de despesas. Afinal, no mínimo suportará os custos de transação inevitáveis para a pactuação de um acordo, quando não tiver que contar com a assistência profissional para tanto. Todavia, parece possível aceitar a hipótese de que os custos necessários para a pacificação de uma disputa extrajudicialmente são usualmente menores do que aqueles envolvidos em um litígio judicial, tanto que a maior parte dos conflitos sociais não deságuam no judiciário ${ }^{30}$.

Nesse passo, o valor máximo que um potencial réu estaria disposto a conceder para evitar um litígio em juízo seria uma função do que despenderia no caso de êxito em juízo da parte contrária, ponderado pela probabilidade de que a eventual demanda fosse julgada procedente, acrescendo-se, ainda, por um lado, todos os custos que, potencialmente, suportaria para litigar em juízo e subtraindo-se, por outro lado, os custos que arcaria para entabular uma solução extrajudicial. Por simplificação, se consideram conjuntamente, em cada variável, todo e qualquer custo relacionado a estar em juízo, bem como todo e qualquer custo relativo a solucionar, extrajudicialmente, o conflito.

Em singela formulação matemática, tal montante máximo a ser potencialmente oferecido pelo réu em uma negociação seria ${ }^{31}$ :

$$
\text { p.D }+C_{L}-C e, \text { em que: }
$$

p - probabilidade de procedência da demanda a ser ajuizada pela parte contrária;

D - dispêndio que o réu terá no caso de procedência da demanda;

CL - custos totais a serem suportados pelo potencial réu para litigar em juízo;

Ce - custos relacionados à solução extrajudicial do conflito.

28 COOTER, Robert; ULEN, Thomas. Direito e Economia. 5. ed. Porto Alegre: Bookman, 2010. p. 428-435.; SPIER, Kathryn E. Litigation. In: POLINSKY, Mitchell; SHAVELL, Steven. (ed.). Handbook of law and economics. Oxford: North-Holland, 2007. v. 1. p. 268-282; MACHADO, Marina Amaral de Ávila et al. Judicialização do acesso a medicamentos no Estado de Minas Gerais, Brasil. Revista de Saúde Pública, v. 45, n. 3, p. 590-598, 2011. p. 394-399; POSNER, Richard A. An Economic Approach to Legal Procedure and Judicial Administration. The Journal of Legal Studies, v. 2, n. 2, p. 399-458, jun. 1973. p. 417-429.

29 POSNER, Richard A. An Economic Approach to Legal Procedure and Judicial Administration. The Journal of Legal Studies, v. 2 , n. 2, p. 399-458, jun. 1973. p. 417-418. Todavia, não se trata de uma condição suficiente, como bem ressalta o autor nas mesmas páginas anteriormente citadas, uma vez que é possível que as partes envolvidas não consigam chegar em um acordo acerca dos exatos termos e montantes envolvidos na negociação. Ou, utilizando-se a nomenclatura de Robert Cooter e Thomas Ulen, não consigam concordar sobre como dividir o excedente cooperativo. COOTER, Robert; ULEN, Thomas. Direito e Economia. 5. ed. Porto Alegre: Bookman, 2010. p. 429.

30 A hipótese de que, em geral, os custos envolvidos em uma negociação extrajudicial são menores do que aqueles que devem ser suportados para se litigar juízo é também adotada pela literatura que se debruça sobre o tema. COOTER, Robert; ULEN, Thomas. Direito e Economia. 5. ed. Porto Alegre: Bookman, 2010. p. 429-430; POSNER, Richard A. An economic approach to legal procedure and judicial administration. The Journal of Legal Studies, v. 2, n. 2, p. 399-458, jun. 1973. p. 417

31 A equação apresentada neste artigo, com singelas modificações, baseia-se em: POSNER, Richard A. An economic approach to legal procedure and judicial administration. The Journal of Legal Studies, v. 2, n. 2, p. 399-458, jun. 1973. p. 419. 
Especificamente em relação à judicialização da saúde, a equação acima merece algumas observações, que indicarão a existência de diversos incentivos para que os entes públicos busquem solucionar, extrajudicialmente, os conflitos com os particulares que manifestem a intenção de ajuizar uma demanda.

A probabilidade de que o processo a ser ajuizado seja julgado procedente é altíssima, conforme estudos empíricos a que já se fez referência. Com algum esforço estatístico, a Administração poderia identificar quais hipóteses são reiteradamente acolhidas e quais, em número minoritário, são rechaçadas pelo Judiciário, adotando estratégias de conciliação ou não, a depender do resultado histórico em juízo daquele tipo de feito.

O dispêndio, por sua vez, muito provavelmente ocorrerá efetivamente caso a pretensão autoral seja acolhida pelo Judiciário. Afinal, na hipótese de a Administração tardar a cumprir voluntariamente a decisão judicial, a jurisprudência admite a constrição patrimonial dos entes públicos para a imediata satisfação da obrigação, inclusive por meio do arresto de verbas públicas, mediante posterior prestação de contas a ser realizada pela parte beneficiada ${ }^{32}$.

Em relação aos custos para litigar em Juízo, os entes públicos arcam com as despesas associadas à manutenção, em seus quadros, de advogados públicos e do pessoal que os auxiliam, bem como com a estrutura física e material imprescindível para o desempenho de suas funções. É usual que, no corpo dos órgãos de representação judicial, existam advogados públicos que se dedicam, exclusivamente, à defesa do ente em ações concernentes ao direito à saúde. Naturalmente, a despesa pública necessária para a manutenção de tal estrutura não é desprezível.

Especificamente quanto aos Estados e à União, há outro fator a ser destacado no que tange aos custos dos litígios judiciais. De fato, o dispêndio de tais entes não se limita ao corpo de advogados públicos e à estrutura correlata. Também arcam com os custos advocatícios da parte contrária quando assistida pela Defensoria Pública. Custeiam, em adição, a atuação do Ministério Público, eventualmente necessária em tais feitos. Suportam, ainda, a maior parte das despesas concernentes à manutenção, em suas esferas, do Poder Judiciário, que processará e julgará, dentre outras causas, aquelas atinentes à judicialização da saúde, com a frequente concessão do benefício da gratuidade de justiça, como já examinado.

Convém ressaltar que o custo para o processamento e julgamento de uma demanda judicial é bastante expressivo. De acordo com a pesquisa denominada Índice de Desempenho da Justiça - IDJus, do Centro de Pesquisas sobre o Sistema de Justiça Brasileiro do Instituto Brasiliense de Direito Público, o custo médio de um processo no Brasil poderia ser estimado em $\mathrm{R} \$ 2.369,73^{33}$. Tratando apenas de execuções fiscais, o Instituto de Pesquisa Econômica Aplicada - IPEA já apontou que o custo médio provável dos insumos diretamente empregados no processamento dos feitos em primeira instância seria de $\mathrm{R} \$ 1.854,23^{34}$. Independentemente das críticas metodológicas que eventualmente possam ser tecidas a tais estudos, não será irrelevante o custo médio a ser suportado pelo Poder Público tão somente em razão da tramitação e julgamento de uma demanda judicial.

Portanto, diferentemente do que ocorre com os particulares ou até mesmo com os Municípios, uma demanda judicial acarreta, para Estado e União enquanto réus, custos que não se limitam àqueles atinentes

32 Em julgamento conforme procedimento previsto para recursos repetitivos, o STJ firmou a tese de que "tratando-se de fornecimento de medicamentos, cabe ao Juiz adotar medidas eficazes à efetivação de suas decisões, podendo, se necessário, determinar até mesmo o sequestro de valores do devedor (bloqueio), segundo o seu prudente arbítrio, e sempre com adequada fundamentação". Nesse sentido, v. Resp n 1069810, Relator Min. Napoleão Nunes Maia Filho, Data de Julgamento 23 out. 2013.

33 O dado se refere ao ano de 2013. O custo médio do processo foi definido e calculado dividindo-se a despesa total da Justiça pelo número total de processos baixados. Centro de Pesquisas sobre o Sistema de Justiça Brasileiro. Índice de Desempenho da Justiça - IDJus 2013. Disponível em: http://cpjus.idp.edu.br/wp-content/uploads/2015/03/IDJUSn4_relatorio_pesquisa_23. 02.15.pdf. Acesso em: 09 mar. 2018.

34 O IPEA buscou diferenciar o custo médio total provável da execução fiscal, que seria de R \$ 4.685,39, do custo médio das movimentações do processo, no valor de $\mathrm{R} \$ 1.854,23$, que excluiria os custos dos processos parados e da mão-de-obra empregada em atuações do Judiciário que não estão relacionadas às suas atividades-fim. INSTITUTO DE PESQUISA ECONÔMICA E APLICADA. Comunicados do IPE $A$ no 83 - Custo unitário do processo de execução fiscal na Justiça Federal. p. 9-10. Disponível em: http://www.ipea.gov.br/portal/images/stories/PDFs/comunicado/110331_comunicadoipea83.pdf. Acesso em: 09 mar. 2018. 
às suas próprias defesas em juízo. Tal circunstância precisa ser considerada quando do cálculo sobre a racionalidade, economicidade e eficiência de celebração de um acordo para a solução extrajudicial de um conflito.

Nesse cenário, é possível perceber de plano que, para os entes públicos, não parece razoável permitir o ajuizamento de uma demanda cuja pretensão seja a de obter um item em saúde que tenha custo menor do que o custo total que suportarão em razão do litígio, ponderado pela (alta) probabilidade de sucumbência da Administração.

Indo além, com algum esforço estatístico e eventual análise das prescrições médicas em poder dos pacientes dispostos a ajuizar uma demanda, os entes públicos poderiam tentar identificar as hipóteses em que a sucumbência em juízo é muito provável, quando não certa, uma vez que, nesses casos, alcançar uma solução extrajudicial para o conflito significaria ao menos economizar a diferença entre os custos atinentes à judicialização e os custos relacionados à solução extrajudicial, que são usualmente menores.

Por exemplo, é de duvidosa racionalidade que o ente público permita o ajuizamento em face de si de uma demanda atinente a uma prestação que já se encontra padronizada para dispensação pelo SUS, mas que, eventualmente, por irregularidade do estoque, não se encontre à disposição na ponta do sistema. Ora, nessas hipóteses, o próprio ente público já se obrigou a fornecer o item, não havendo, como regra, resistência jurídica pertinente ao cumprimento da obrigação, sendo a sucumbência muito provável, portanto. A solução extrajudicial do conflito, no caso, ao menos permitiria a economia dos custos de judicialização.

Reconduzindo-se o raciocínio à equação vista acima, para o ente público réu, seria vantajoso solucionar, extrajudicialmente, o conflito oferecendo um valor máximo equivalente a p.D + CL - Ce. No caso de altíssima probabilidade de procedência da demanda (p), um acordo para ofertar extrajudicialmente o tratamento demandado seria uma estratégia racional e amparada pela eficiência e economicidade, haja vista que provavelmente representaria um dispêndio menor do que o teto que a entidade deveria estar disposta a pagar para evitar a judicialização da questão, sendo suficientemente baixos os custos para solução extrajudicial (Ce) e suficientemente altos os custos de litígio (CL). Sob a ótica de Estados e União, a propensão ao acordo deveria ser ainda maior, haja vista que o custo para litígio (CL) envolve, também, os custos de processamento e julgamento do processo e, possivelmente, os custos advocatícios da parte contrária.

Talvez, seguindo esse caminho, no Estado do Rio de Janeiro, por exemplo, publicou-se o Decreto $\mathrm{n}^{\circ}$ 45.034/2014, que pretendia regulamentar o procedimento para a realização de acordos, no âmbito da Câmara de Resolução de Litígios em Saúde existente naquele ente público, visando ao fornecimento extrajudicial de medicamentos. O mencionado decreto previa diversos requisitos para a celebração da pactuação, dentre os quais figurava que as tratativas somente poderiam se dar sobre patologias e medicamentos, a serem indicados pela Secretaria de Saúde, relativos a hipóteses em que o Estado já houvesse sido condenado pelo Judiciário, em decisão de mérito confirmada em segundo grau de jurisdição, ao fornecimento da prestação. No mais, dentre outras exigências, os fármacos deveriam ser registrados pela Anvisa, os pacientes deveriam apresentar laudo e receita médica atualizados emitidos por profissional habilitado vinculado ao SUS que demonstrassem a necessidade de utilização do produto e deveria haver parecer elaborado por comitê técnico indicado pela Secretaria de Estado de Saúde que, após a avaliação dos documentos médicos do paciente, concluísse fundamentadamente pela necessidade de utilização do medicamento em razão da inexistência de alternativa terapêutica já incorporada ao SUS para o tratamento da patologia ou, quando houvesse, pela impossibilidade de sua utilização pelo interessado.

Todavia, a despeito do avanço que tal decreto poderia representar à solução extrajudicial de conflitos em saúde, até o momento da elaboração do presente artigo, o seu teor, ainda, não havia sido efetivamente implementado na rotina da Administração Pública, inexistindo, salvo equívoco, notícias de acordo celebrado sob seu fundamento. 
Se os entes públicos se deparam com uma estrutura de incentivos que os deveria conduzir ao maior empenho na tentativa de obtenção de soluções extrajudiciais, por que tais acordos parecem ser pouco frequentes no dia a dia da Administração?

A literatura de Análise Econômica do Direito tradicionalmente indica algumas hipóteses explicativas para a não ocorrência de acordos mesmo quando há indícios de que seria a solução ótima para as partes. A primeira envolveria a noção de assimetria de informações, que se apresentaria, em apertadíssima síntese, sob duas formas: (i) viés cognitivo de excesso de otimismo, relativo à tendência humana de superestimar suas próprias capacidades e, em juízo, considerar que possui uma maior chance de vitória do que efetivamente possui; e (ii) desequilíbrio de informações, em que uma partes não consegue identificar, adequadamente, as chances de êxito de seu oponente e, por isso, receia em fazer um acordo desvantajoso ${ }^{35}$.

Uma segunda hipótese diz respeito aos custos altos de transação e de celebração de acordo, que conduziriam à preferência pelo ajuizamento da demanda ${ }^{36}$. Poder-se-ia, ainda, cogitar uma terceira hipótese, relacionada a um aspecto temporal, em que uma das partes gostaria de procrastinar a resolução do conflito, ou seja, de voluntariamente tardar a adimplir eventual obrigação.

Ocorre que tais hipóteses tradicionais não parecem suficientes para explicar o porquê da baixa frequência de conciliações na seara em exame. No que tange à assimetria informacional, os entes são assistidos por advogados públicos que, certamente, conhecem a probabilidade de resultado dos litígios, uma vez que lidam com o tema diariamente e não parecem ter qualquer razão pessoal para superestimar a chance de êxito para além do histórico de resultados que observam pela experiência. Quanto aos custos do acordo, levando-se em conta os altos custos de litígio que os entes públicos enfrentam, em especial Estados e União, como já examinado nesse trabalho, parece razoável presumir que dificilmente o custo transacional para um acordo seria significativo quando considerada a estrutura de custos do ente público como um todo. Por fim, quanto ao eventual desejo de procrastinação, tal hipótese não parece relevante especificamente para o caso da judicialização da saúde, uma vez que, além de serem frequentes decisões de antecipação de tutela determinado a imediata entrega da prestação sanitária, os tribunais superiores pacificaram o entendimento, como já destacado, quanto à possibilidade de arrestos nas contas dos entes públicos para cumprimento imediato das decisões. Assim, o dispêndio - caso acolhida a pretensão autoral, ainda que apenas em cognição sumária — torna-se célere e inevitável, de modo que não se justificaria uma indevida tentativa de voluntária procrastinação por meio do encaminhamento do litígio ao Judiciário.

Assim, considerando-se que as teorias explicativas tradicionais não parecem ser suficientes, há de se buscar outras mais adequadas ao caso em tela. Apresentam-se, abaixo, seis novas hipóteses. Como se verá, tais fatores podem ou dificultar a correta percepção dos incentivos que são postos à Administração ou de fato os modificar, tornando menos óbvia a opção pela conciliação, ao menos para todas as entidades federativas que frequentemente figuram no polo passivo das demandas em tela.

\subsubsection{Diferença entre custos marginais e custos médios}

O custo médio de litígio relativo a cada demanda judicial pode ser significativo, nos termos acima expostos. Todavia, o custo marginal, ou seja, o custo para atuar em um processo judicial a mais pode não ser tão expressivo.

35 KLEIN, Benjamin; PRIEST, George L. The selection of disputes for litigation. The Journal of Legal Studies, v. 13, n. 1, p. 1-55, jan. 1984; BEBCHUK, Lucian Arye. Litigation and settlement under imperfect information. The RAND Journal of Economics, v. 15, n. 3, p. 404-415, 1984.

36 Como exemplo de texto que caminha nessa direção argumentativa, trabalhando, ainda, a distribuição do poder de barganha. ANDERLINI, Luca; FELLI, Leonardo; IMMORDINO, Giovanni. Costly Pretrial Agreements. Disponível em: http:// faculty.georgetown.edu/la2/Pretrial.pdf. Acesso em: 15 set. 2018. 
Com efeito, a estrutura administrativa e o corpo burocrático da advocacia pública, do Poder Judiciário, do Ministério Público e das Defensorias Públicas já se encontram montados e em operação, razão pela qual o incremento de uma demanda a mais, por si só, não representa um impacto financeiro considerável.

Assim, somente soluções sistêmicas — que evitem uma quantidade expressiva de demandas — impactariam a estrutura de custos totais suportados pelos entes públicos e permitiriam a reorganização dos agentes públicos envolvidos para o desempenho de outras atividades dentro de seus órgãos.

\subsubsection{Inexistência de dados objetivos para a tomada de decisões racionais}

A Administração Pública brasileira não está habituada a coletar dados úteis para subsidiar a sua tomada de decisão. Informações objetivas, atinentes a custos de suas estruturas administrativas ou a resultados obtidos nos litígios em que se insere, possivelmente, não estão disponíveis na maior parte dos entes federativos. Nesse cenário, o emprego de métodos quantitativos não faz parte da rotina da Administração de boa parte dos entes federativos.

Assim, é provável que, em regra, o Poder Público, no momento presente, sequer tenha as informações necessárias para verificar, matematicamente, se a celebração de um acordo extrajudicial, além de eventualmente auxiliar a promover o direito fundamental de um particular de modo mais imediato, poderia também ser uma medida eficiente e de acordo com a economicidade para a Fazenda.

Sem a presença de dados objetivos e confiáveis e inexistindo cálculo de custos envolvidos, a opção pela solução extrajudicial pode se tornar pouco intuitiva para o gestor público.

\subsubsection{Litigância em litisconsórcio passivo e ausência de regras objetivas quanto a quem su- portará os ônus financeiros em cada hipótese}

As demandas judiciais nas quais se pleiteiam prestações de saúde são, rotineiramente, ajuizadas mediante a constituição de litisconsórcio passivo entre os entes públicos envolvidos, em especial entre o Estado e a municipalidade em que o autor reside.

Segundo o entendimento jurisprudencial consolidado pelo STF, reafirmando quando do julgamento do recurso extraordinário $\mathrm{n}^{\circ} 855.178$, os entes federados teriam responsabilidade solidária quanto ao fornecimento de tratamento médico adequado. $\mathrm{O}$ entendimento merece críticas doutrinárias sob diversos aspec$\operatorname{tos}^{37}$, mas aqui cabe observar os incentivos que acaba por produzir.

Quando o objeto da controvérsia judicial se refere a uma prestação que não está padronizada no SUS, ou seja, em relação à qual nenhum ente público obrigou-se ao fornecimento, não há um critério inequívoco para a definição de qual pessoa jurídica teria o primário dever de cumprir o comando judicial. Em se tratando de uma responsabilidade solidária, qualquer um deles pode ser demandado, independentemente da espécie de prestação, para o cumprimento imediato, o que leva alguns Magistrados a, por vezes, direcionar a determinação em um primeiro momento a apenas um dos entes, que lhes pareça estar em melhor posição para arcar com o comando. Embora compensações financeiras ou outras medidas de cooperação pudessem ocorrer entre as entidades federadas que restaram solidariamente condenadas, na prática tais mecanismos nem sempre existem de fato.

Nesse passo, pode-se imaginar um Município que suporta ônus muito além daqueles previstos na repartição de competências do SUS ou um Estado que, em razão da judicialização, rotineiramente, assuma atribuições que, tipicamente, deveriam ser dos Municípios ou da União.

37 SARMENTO, Daniel; TELLES, Cristina. Judicialização da saúde e responsabilidade federativa: solidariedade ou subsidiariedade? In: ASENSI, Felipe Dutra; PINHEIRO, Roseni (org.) Direito sanitário. Rio de Janeiro: Elsevier, 2012. 
Assim, a depender de como se posiciona quanto ao atendimento dos comandos judiciais em seu desfavor, um ente público pode enfrentar maiores ou menores incentivos à conciliação prévia, uma vez que, na realidade da judicialização e das práticas administrativas de um determinado lugar, algumas entidades federativas podem suportar maiores ou menores ônus financeiros do que outras para atender aos comandos judiciais.

\subsubsection{Potes orçamentários diversos}

Não são apenas os diferentes entes públicos que lidam com incentivos diversos entre si. Mesmo dentro de uma mesma pessoa jurídica, seus diferentes órgãos podem observar incentivos distintos, que justificarão diferentes comportamentos sobre um mesmo tema.

Observou-se, anteriormente, que União e Estados se deparam com custos de litígios significativos. Além disso, caso restem derrotadas judicialmente, deverão ainda, naturalmente, arcar com a prestação requerida.

Ocorre que, embora todos os custos devam ser suportados pela pessoa jurídica, os órgãos que arcarão com tais despesas, possivelmente, serão distintos. Com efeito, no caso de sucumbência do ente, a obrigação de direito material atinente ao objeto da demanda será cumprida pelo Ministério ou Secretaria de Saúde. Já os custos concernentes, por exemplo, ao funcionamento adequado do Judiciário não possuem relação com os órgãos especializados em saúde. Em outros termos, para o Ministério ou para as Secretarias de Saúde, o custo relativo à existência, por si só, de uma demanda judicial a mais (ou seja, o custo atinente à movimentação da máquina judiciária e dos demais órgãos a ela relacionados) será zero ou praticamente zero. Tal despesa estará relacionada a outro órgão daquela entidade administrativa, como, hipoteticamente, ao Ministério ou Secretaria da Fazenda ou do Planejamento, responsável por repassar o orçamento devido ao Judiciário. Para o Ministério ou a Secretaria de Saúde, o único custo relevante será aquele atinente ao efetivo cumprimento da obrigação.

Assim, as diferentes espécies de custos atinentes à judicialização incidem sobre potes orçamentários diversos entre si. Como cada órgão é afetado apenas por uma parcela dos custos que recaem sobre o ente público, restam incentivados a considerar em suas estratégias tão somente os custos suportados por si, e não pela pessoa jurídica como um todo. Caberia, assim, ao ente público envolvido computar e somar as diferentes despesas suportadas por seus órgãos, o que exigiria adequada coordenação entre as suas diferentes unidades de poder.

\subsubsection{Pouca coordenação entre diferentes órgãos e entes}

Os diferentes órgãos que suportam distintos custos atinentes à judicialização integram uma única pessoa jurídica. Portanto, as decisões estratégicas da Administração Pública deveriam, idealmente, considerar os custos integrais suportados pelo ente, e não os incentivos com os quais cada um dos seus órgãos se depara.

Igualmente, ainda que o comando judicial seja, em um primeiro momento, cumprido integralmente apenas por um dos entes que figura no litisconsórcio passivo, os demais poderiam compartilhar da responsabilidade, nos termos pactuados entre os diferentes entes públicos envolvidos.

Todavia, às vezes, a coordenação entre diferentes órgãos e a ainda mais complexa coordenação entre diferentes entes públicos não ocorre como se poderia idealmente imaginar, razão pela qual as diferentes esferas podem adotar estratégias e comportamentos de acordo com as escolhas que sejam racionais para melhor atenderem seus interesses individuais. 
Por fim, como última hipótese a buscar explicar a pouca frequência das soluções extrajudiciais para os conflitos, poder-se-ia cogitar da eventual tentativa, por parte dos entes públicos, de modificar o entendimento jurisprudencial dominante adotado acerca do tema pelos Tribunais, buscando revertê-lo, em juízo, mediante a apresentação de resposta e o manejo dos recursos cabíveis. De fato, sendo verdadeira tal hipótese, a propensão à solução extrajudicial do conflito seria menor.

Ocorre que, como já exposto, os principais pontos jurídicos controvertidos acerca da judicialização em saúde já se encontram afetados para decisão pelo STF, com repercussão geral reconhecida. Portanto, a resistência em todas as hipóteses não parece ser uma estratégia economicamente racional, uma vez que, como visto, a judicialização por si só já representa um custo. Ao menos, até o julgamento definitivo de tais recursos paradigmas por parte do STF, a jurisprudência atualmente firmada será uma realidade com a qual a Administração terá que conviver e que precisará considerar quando da decisão por suas estratégias processuais.

\section{Considerações finais}

Ao longo do presente trabalho, buscou-se examinar os incentivos que conduzem à judicialização em massa, bem como de que modo tal realidade posta acarreta ou deveria acarretar incentivos para que a Administração busque a solução extrajudicial de conflitos.

As principais conclusões expostas, obtidas com base nos dados e argumentos deduzidos, podem ser sintetizadas nos seguintes termos:

1. A judicialização da saúde é um fenômeno que, pela quantidade de demandas judiciais envolvidas, consome uma quantidade expressiva de recursos - humanos e financeiros - do Poder Público;

2. As demandas por prestações de saúde são amplamente acolhidas pelo Judiciário, que apresenta, em geral, uma compreensão bastante abrangente quanto ao que estaria contido no direito à saúde constitucionalmente previsto;

3. A estrutura de incentivos posta aponta para a tendência de incremento na quantidade de demandas da espécie;

4. Considerando o entendimento judicial majoritário como um dado ou fato posto - que tende a não se alterar ao menos até o julgamento definitivo dos pontos juridicamente controvertidos pelos Tribunais Superiores - a Administração Pública se depara com incentivos para a busca por soluções extrajudiciais dos conflitos em diversas hipóteses;

5. Especialmente para União e Estados, a propensão ao acordo deveria ser maior, haja vista que os seus custos para litígio judicial englobam também aqueles relativos ao processamento e julgamento das demandas e, possivelmente, os custos advocatícios da parte contrária, quando os pacientes-autores são assistidos pela Defensoria Pública;

6. Todavia, apesar do cenário que aponta para a racionalidade da mais efetiva busca pela solução judicial dos conflitos, tais acordos, na prática, não parecem ser frequentes. Apresentam-se, assim, seis hipóteses explicativas para essa realidade, quais sejam, a diferença entre os custos marginais e os custos médios suportados pelo Poder Público, a inexistência de dados objetivos para a tomada de decisões racionais, a litigância em litisconsórcio passivo somada à ausência de regras objetivas quanto a quem suportará os ônus financeiros em cada hipótese, o fracionamento 
orçamentário entre os diferentes órgãos, a pouca coordenação entre diferentes órgãos e entes e a intenção de resistir ao entendimento dominante adotado pelos Tribunais. Tais hipóteses, se verdadeiras, podem de fato dificultar a correta compreensão dos incentivos que se colocam para a Administração ou mesmo os modificar, talvez tornando a opção pela conciliação menos atraente para algumas das entidades federativas.

\section{REFERÊNCIAS}

ANDERLINI, Luca; FELLI, Leonardo; IMMORDINO, Giovanni. Costly Pretrial Agreements. Disponível em: http:/ / faculty.georgetown.edu/la2/Pretrial.pdf. Acesso em: 15 set. 2018.

ARAKE, Henrique; GICO JUNIOR, Ivo. De graça, até injeção na testa: análise juseconômica da gratuidade de justiça. Economic Analysis of Law Review, v. 5, n. 1, p. 166-178, jan./jun., 2014.

BARCELLOS, Ana Paula de. O direito a prestações de saúde: complexidades, mínimo existencial e o valor das abordagens coletiva e abstrata. Revista da Defensoria Pública do Estado de São Paulo, ano 1, n. 1, jul./dez. 2008 .

BARCELLOS, Ana Paula de. O direito constitucional à saúde: o caminho percorrido e algumas reflexões para o futuro. In: FERRARI, Sergio; MENDONÇA, José Vicente. Direito em público: homenagem ao professor Paulo Braga Galvão. Rio de Janeiro: Lúmen Juris, 2016.

BARROSO, Luís Roberto. Da falta de efetividade à judicialização excessiva: Direito à Saúde, fornecimento gratuito de medicamentos e parâmetros para a atuação judicial. Disponível em: http://pfdc.pgr.mpf.mp.br/ atuacao-e-conteudos-de-apoio/publicacoes/saude/Saude_-_judicializacao_-_Luis_Roberto_Barroso.pdf. Acesso em: 09 jan. 2018.

BEBCHUK, Lucian Arye. Litigation and settlement under imperfect information. The RAND Journal of Economics, v. 15, n. 3, p. 404-415, 1984.

BRASIL. Advocacia-Geral da União. Intervenção judicial na saúde pública: panorama no âmbito da Justiça Federal e apontamentos na seara das Justiças Estaduais. Disponível em: http://portalarquivos.saude.gov.br/images/pdf/2014/maio/29/Panorama-da-judicializa----o---2012---modificado-em-junho-de-2013.pdf. Acesso em: 03 fev. 2018.

BRASIL. Conselho Nacional de Justiça. Brasil tem mais de 240 mil processos na área de saúde. Disponível em: http://www.cnj.jus.br/noticias/cnj/56636-brasil-tem-mais-de-240-mil-processos-na-area-de-saude. Acesso em: 03 fev. 2018.

BRASIL. Conselho Nacional de Justiça. Justiça em números: demandas por classe e assunto - 2016. Disponível em: http://paineis.cnj.jus.br/QvAJAXZfc/opendoc.htm?document=qvw_l\%2FPainelCNJ.qvw\&host=Q VS\%40neodimio03\&anonymous=true\&sheet=shResumoDespFT. Acesso em: 23 jan. 2018.

BRASIL. Conselho Nacional de Justiça. Justiça em números: indicadores do Poder Judiciário em 2016 - Total. Disponível em: http://paineis.cnj.jus.br/QvAJAXZfc/opendoc .htm?document=qvw_l\%2FPainelCNJ.qv w\&host=QVS\%40neodimio03\&anonymous=true\&sheet=shResumoDespFT. Acesso em: 23 jan. 2018.

BRASIL. Tribunal de Contas da União. Aumentam os gastos públicos com judicialização da saúde. Disponível em: https://portal.tcu.gov.br/imprensa/noticias/aumentam-os-gastos-publicos-com-judicializacao-da-saude. htm. Acesso em: 26 jan. 2018.

CARVALHO, Victor Aguiar de. A política pública na caneta do médico: avanços e incertezas no julgamento sobre fornecimento de medicamentos não incorporados ao SUS. Jota, 18 maio 2018. Disponível em: 
https://www.jota.info/opiniao-e-analise/artigos/a-politica-publica-na-caneta-do-medico-18052018. Acesso em: 15 set. 2018.

Centro de Pesquisas sobre o Sistema de Justiça Brasileiro. Índice de Desempenho da Justiça - IDJus 2013. Disponível em: http://cpjus.idp.edu.br/wp-content/uploads/2015/03/IDJUSn4_relatorio_pesquisa_23. 02.15.pdf. Acesso em: 09 mar. 2018.

COOTER, Robert; ULEN, Thomas. Direito e Economia. 5. ed. Porto Alegre: Bookman, 2010.

FERRAZ, Octavio Luiz Motta. The right to health in the courts of Brazil: worsening health inequities? Health and Human Rights Journal, v. 11, n. 2, p. 33-45, 2009.

GIAMBIAGI, Fabio. Capitalismo: modo de usar - porque o Brasil precisa aprender a lidar com a melhor forma de organização econômica que o ser humano já inventou. Rio de Janeiro: Elsevier, 2015.

INSTITUTO DE PESQUISA ECONÔMICA E APLICADA. Comunicados do IPE $A n^{\circ} 83$ - Custo unitário do processo de execução fiscal na Justiça Federal. p. 9-10. Disponível em: http://www.ipea.gov.br/portal/ images/stories/PDFs/comunicado/110331_comunicadoipea83.pdf. Acesso em: 09 mar. 2018.

INTERFARMA. Por que o brasileiro recorre à justiça para adquirir medicamentos? Entenda o que é a judicialização da saúde. Disponível em: https://www.interfarma.org.br/public/ files/biblioteca/101-por-que-o-brasileiro-vai-a-justiaa-em-busca-de-medicamentos-site.pdf. Acesso em: 26 jan. 2018.

KLEIN, Benjamin; PRIEST, George L. The selection of disputes for litigation. The Journal of Legal Studies, v. 13, n. 1, p. 1-55, jan. 1984.

MACHADO, Marina Amaral de Ávila et al. Judicialização do acesso a medicamentos no Estado de Minas Gerais, Brasil. Revista de Saúde Pública, v. 45, n. 3, p. 590-598, 2011.

MERCURO, Nicholas; MEDEMA, Steven G. Economics and the Law: from Posner to Postmodernism and beyond. 2. ed. Princeton: Princeton University Press, 2006.

PEREIRA, José Gilberto; PEPE, Vera Lúcia Edais. Acesso a medicamentos por via judicial no Paraná: aplicação de um modelo metodológico para análise e monitoramento das demandas judiciais. Revista de Direito Sanitário, v. 15, n. 2, p. 30-45, jul./out. 2014.

POSNER, Richard A. An Economic Approach to Legal Procedure and Judicial Administration. The Journal of Legal Studies, v. 2, n. 2, p. 399-458, jun. 1973.

PRADO, Mariana Mota. The Debatable Role of Courts in Brazil's Health Care System: Does Litigation Harm or Help? Journal of Law, Medicine and Ethics, v. 41, n. 1, p. 124-137, 2013.

RIO DE JANEIRO. Tribunal de Justiça do Rio de Janeiro. Processos na área de saúde atingem no TJRJ a marca de mais de meio milhão em 2017. Disponível em: http://www.tjrj.jus.br/web/guest/home/-/noticias/visualizar/55518. Acesso em: 14 mar. 2018.

ROSENBERG, David; SHAVELL, Steven. A model in which suits are brought for their nuisance value. Internacional Review of Law and Economics, v. 5, p. 3-13, 1985.

SARMENTO, Daniel; TELLES, Cristina. Judicialização da saúde e responsabilidade federativa: solidariedade ou subsidiariedade? In: ASENSI, Felipe Dutra; PINHEIRO, Roseni (org.) Direito sanitário. Rio de Janeiro: Elsevier, 2012.

SILVA, Virgílio Afonso da; TERRAZAS, Fernanda Vargas. Claiming the right to health in Brazilian courts: the exclusion of the already excluded. Disponível em: https://papers.ssrn.com/sol3/papers.cfm?abstract_ id=1133620. Acesso em: 24 jan. 2018.

SPIER, Kathryn E. Litigation. In: POLINSKY, Mitchell; SHAVELL, Steven. (ed.). Handbook of law and economics. Oxford: North-Holland, 2007. v. 1. p. 268-282. 
TIMM, Luciano Benetti. Direito à saúde e a maneira mais eficiente de prover direitos fundamentais - uma perspectiva de direito e economia? In: NOBRE, Milton Augusto de Brito; SILVA, Ricardo Augusto Dias da (coord.). O CNJ e os desafios da efetivaşão do direito à saúde. 2. ed. Belo Horizonte: Fórum, 2013.

VENTURA, Miriam et al. Judicialização da saúde, acesso à justiça e efetividade do direito à saúde. Physis Revista de Saúde Coletiva, v. 20, n. 1, p. 77-100, 2010.

VIEIRA, Fabiola Sulpino; ZUCCHI, Paola. Distorções causadas pelas ações judiciais à política de medicamentos no Brasil. Revista Saúde Pública, v. 41, n. 2, p. 214-222, 2007.

WANG, Daniel Wei Liang. Courts as healthcare policy-makers: the problem, the responses to the problem and problems in the responses. Disponível em: http://bibliotecadigital.fgv.br/dspace/bitstream/ handle/10438/11198/RPS_75_final.pdf?sequence=1\&isAllowed=y. Acesso em: 23 jan. 2018.

WANG, Daniel Wei Liang. Right to health litigation in Brazil: the problem and the Institutional Responses. Human Rights Law Review, v. 15, p. 617-641, 2015.

Revisado pela biblioteca em: 24/01/2019

Informações incompletas em vermelho 
Para publicar na revista Brasileira de Políticas Públicas, acesse o endereço eletrônico www.rbpp.uniceub.br

Observe as normas de publicação, para facilitar e agilizar o trabalho de edição. 